\title{
Multifunctional cellulolytic activities from Streptomyces osmaniensis for agricultural and enzyme industry
}

\author{
Nuntavun Riddech ${ }^{*}$, Nutthapon Saharm ${ }^{2}$, Chanokporn Chaisawang ${ }^{2}$, Paweenut Pongtongmee ${ }^{2}$, Sutumporn \\ Boonchern ${ }^{2}$, Pornrapee Sarin ${ }^{3}$ and Thanaporn Phibunwatthanawong ${ }^{3}$
}

${ }^{1}$ Department of Microbiology, Faculty of Science, Khon Kaen University, Thailand.
${ }^{2}$ Undergraduate School of Department of Microbiology, Faculty of Science, Khon Kaen University, Thailand.
${ }^{3}$ Graduate School of Department of Microbiology, Faculty of Science, Khon Kaen University, Thailand. Email: nunrid@kku.ac.th

Received 27 July 2015; Received in revised form 14 August 2015; Accepted 14 August 2015

\begin{abstract}
Aims: The aims of this study were to screen for cellulose degradation activity from actinomycetes using agar plate method, detect $\beta$-glucosidase activity, morphology and molecular taxonomy study.

Methodology and results: Preliminary screening for cellulose degrading Actinomycete was done on the carboxymethyl cellulose agar (CMC agar) and detected by flooding with gram iodine. It was found that 190 isolates were cellulase producing actinomycetes. Actinomycete isolate CDF2L1D13 showed maximum clear zone around the colony and the highest hydrolysis capacity value was 3.93. $\beta$-glucosidase activity was examined by measuring the amount of paranitrophenol (pNP) librated by Tako method. Study on comparison of the enzyme activity in CMC broth with alternative broth was performed. The highest $\beta$-glucosidase activity was found on alternative production medium that supplemented rice bran as a carbon source. $\beta$-glucosidase activity was $0.401 \mathrm{U} / \mathrm{mL}$. The optimum $\mathrm{pH}$ of alternative production medium for producing $\beta$-glucosidase was at $\mathrm{pH}$ value 7 and incubated at $30{ }^{\circ} \mathrm{C}$. Isolate CDF2L1D13 was antagonistic actinomycete against rice blast pathogen (Pyricularia oryzae). The character of this isolate was showed white color of substrate mycelium, white color of aerial mycelium, gray spore and spiral spore chain. Actinomycete isolate CDF2L1D13 was phylogenetically similar to Streptomyces osmaniensis.

Conclusion, significance and impact of study: The result from this study indicated that Streptomyces osmaniensis has the potential on $\beta$-glucosidase production and it is antagonistic actinomycete against Pyricularia oryzae.
\end{abstract}

Keywords: $\beta$-glucosidase, actinomycetes, rice bran, rice blast pathogen

\section{INTRODUCTION}

Actinomycetes produce various extracellular enzymes. Some enzymes play an important role in the degradation of cellulose. Cellulases is the key-player to hydrolyse cellulose. It is a complex enzyme which consists of endoglucanases (EC 3.2.1.4), cellobiohydrolases (1,4- $\beta$ D-glucan cellobiohydrolase; EC 3.2.1.91) and $\beta$ glucosidases ( $\beta$-D-glucoside glucohydrolase; EC 3.2.1.21). Among them, $\beta$-glucosidase hydrolyzes glucose dimmers and cellulose oligosaccharide to produce glucose (Tako et al., 2009). $\beta$-glucosidase is an important enzyme in the land carbon cycle, in the production of glucose, which constitutes an important energy source for the microbial mass (Tabatabai, 1994). Glucose is as a vital source of energy for bioethanol production. Moreover, the determination of $\beta$-glucosidase activity, among other hydrolytic enzyme activities, has been suggested as a good indicator of soil quality (Dick et al., 1996). Actinomycetes are widely spread in soil. Several researchers have reported that $\beta$-glucosidase could be obtained from actinomycetes. For example, Veiga et al. (1983) isolated 36 cellulolytic actinomycetes from marine sediment using cellulose azure method for screening. In addition, actinomycetes can inhibit the growth of other microorganisms by producing antibiotics. Some actinomycetes isolated from soil can inhibit the growth of plant pathogens such as Fusarium palmivora, Bacillus subtilis, Pantoae dipersa and Ralstonia solanacearum (Jeffrey, 2008). To find out about multifunctional in actinomycetes is an interesting issue and it will be useful for agricultural and enzyme industry.

In this study, cellulose degrading actinomycetes were isolated from the soil of the Chulabhorn Dam area, Thailand. The isolate having the highest cellulose activity was selected for studying on $\beta$-glucosidase activity and identified by microscopic morphology and molecular taxonomy. Optimum condition $(\mathrm{pH})$ of this isolate for the enzyme fermentation was determined and the effect of supplementation of rice bran in the culture medium was 
examined. In addition, the inhibitory activity against plant pathogen was tested.

\section{MATERIALS AND METHODS}

\section{Soil sampling and soil pretreatment}

Root zone soil samples from Chulabhron Dam, Chaiyapoom province, Thailand, were collected for the isolation of cellulose degrading actinomycetes. Actinomycetes in soil samples were enriched by incubating soil suspension at $50{ }^{\circ} \mathrm{C}$ in a water bath for 15 $\min$.

\section{Screening of cellulose degrading actinomycetes}

One gram of soil sample was added into $9 \mathrm{~mL}$ of distilled water. Ten-fold serial dilution from $10^{-1}$ to $10^{-8}$ was prepared. A $0.1 \mathrm{~mL}$ of $10^{-8}$ diluted soil suspension was spread on starch casein agar plate. Actinomycetes colonies on agar plate were selected for further testing of cellulose degradation on carboxymethyl cellulose agar (CMC agar).

Actinomycetes were point-inoculated onto CMC agar and incubated at $30^{\circ} \mathrm{C}$ for 5 days. Cellulose degradation activity was detected by flooding Gram's iodine solution on the agar plate for 5 min. Positive results were seen as the clear zone around the colony. Cellulose degradation activity was calculated as the hydrolysis capacity value ( $\mathrm{HC}$ value) from the formula below:

$$
\begin{aligned}
\mathrm{HC} \text { value }= & \text { the ratio of the diameters of clearing } \\
& \text { zone and the colony }
\end{aligned}
$$

The actinomycete isolate CDF2L1D13 having the highest $\mathrm{HC}$ value was selected for further study.

\section{$\beta$-D-glucosidase activity}

The $\beta$-D-glucosidase activity in the culture medium was determined using $p$-nitrophenyl- $\beta$-D-glucopyranoside (PNPG) as the substrate according to the method described by Tako et al. (2009) with slight modification. The reaction mixture consisted of $0.1 \mathrm{~mL}$ of the culture medium, $0.8 \mathrm{~mL}$ of $0.1 \mathrm{M}$ sodium citrate buffer, $\mathrm{pH} 5.0$, and $0.1 \mathrm{~mL}$ of $0.7 \mathrm{mM}$ PNPG solution in the test tube was incubated in a water bath at $50{ }^{\circ} \mathrm{C}$ for $30 \mathrm{~min}$. Then, $2 \mathrm{~mL}$ of $0.1 \mathrm{M}$ sodium carbonate was added to the test tube to stop the reaction. The amount of $p$-nitrophenol released was measured using a spectrophotometer at $405 \mathrm{~nm}$. One international unit (IU) of $\beta$-glucosidase activity was defined as the amount of enzyme required to liberate $1 \mu \mathrm{mol}$ of $p$ nitrophenol per min from the substrate.

\section{Effect of rice bran and CMC supplementation on $\beta$ - glucosidase production}

Effects of the addition of two carbon sources (rice bran and $\mathrm{CMC}$ ) on $\beta$-glucosidase production by the actinomycete were examined. For this purpose, $2 \mathrm{~g}$ of rice bran or $2 \mathrm{~g}$ of $\mathrm{CMC}$ was added to $1000 \mathrm{~mL}$ of the $\beta$ glucosidase production medium. The production medium consisted of $\mathrm{NaNO}_{3} 2.0 \mathrm{~g}, \mathrm{~K}_{2} \mathrm{HPO}_{4} 1.0 \mathrm{~g}, \mathrm{MgSO}_{4} 0.5 \mathrm{~g}$, $\mathrm{KCl} 0.5 \mathrm{~g}$, peptone $0.2 \mathrm{~g}$ and distilled water $1000 \mathrm{~mL}$ with $\mathrm{pH}$ 7. To $50 \mathrm{~mL}$ of the production medium, $0.1 \mathrm{~mL}$ of $10^{8}$ spore/mL of actinomycete isolate CDF2L1D13 suspension was inoculated and incubated at $30^{\circ} \mathrm{C}$ for 15 days. The $\beta$ glucosidase activity in the culture medium was measured as described above.

\section{Determination of optimum $\mathrm{pH}$ for $\beta$-glucosidase production}

To determine the optimal $\mathrm{pH}$ for $\beta$-glucosidase production by the actinomycete isolate CDF2L1D13, $50 \mathrm{~mL}$ of the production medium supplemented with $2 \mathrm{~g}$ of rice bran (the rince bran medium) was prepared and the $\mathrm{pH}$ range was adjusted to 4-9 using $\mathrm{HCL}$ or $\mathrm{NaOH}$. A $0.1 \mathrm{~mL}$ of $10^{8}$ spore/mL isolate was inoculated into the production medium and incubated at $30{ }^{\circ} \mathrm{C}$ for 15 days. At the optimal $\mathrm{pH}$ was determined by the highest $\beta$-glucosidase activity in production medium.

\section{Inhibitory activities of the actinomycete isolate CDF2L1D13 on rice blast pathogen}

Rice blast pathogen, Pyricularia oryzae, was cultured on potato dextrose agar, incubated at $30{ }^{\circ} \mathrm{C}$ for 3 days. The actinomycete isolate CDF2L1D13 was grown on the starch casein agar at $30^{\circ} \mathrm{C}$ for 3 days.

Dual culture technique was used to detect inhibitory activity. A plug of three day old fungal pathogen was placed at the center of the agar plate consisted of the mixture of starch casein agar and potato dextrose agar at the ratio of $1: 1$. The actinomycete isolate CDF2L1D13 was inoculated on the 3 points at $2 \mathrm{~cm}$ inside of the edge of the Petri dish, and incubated at $30{ }^{\circ} \mathrm{C}$ for 5 days. For the control plate, each fungal pathogen was pointinoculated on the mixture medium and cultured at the same condition as the test plate. The radial of the mycelium of fungal pathogen on the control (R1) and the test plate (R2) were measured. Percent of inhibition of radial growth (PIRG) was calculated as the antagonistic activity.

$$
P I R G=\underline{(R 1-R 2)} \times 100
$$

\section{R1}

The PIRG values were categorized according to Živkovicl et al. (2010); $>75 \%=$ very high, $60-75 \%=$ high, $51-60 \%=$ moderate, $<50 \%=$ low

\section{Morphology of the Actinomycete isolate CDF2L1D13}

The morphology of the actinomycete isolate CDF2L1D13 on starch casein agar (SCA) was examined by naked eyes followed by compound microscopy. Cover slip culture technique was used to characterize aerial mycelia and spores arrangement. In brief, a sterile cover slip was inserted into solidified SCA at an angle of $45^{\circ}$. A loopful of 
the isolate CDF2L1D13 was streaked along the line, where the cover slip meets the agar, and the plates was incubated at $30{ }^{\circ} \mathrm{C}$ for 7 days. Then, the cover slip was placed on a new slide and stained with crystal violet (Sekar and Mohanraj, 2013).

\section{Molecular identification of the Actinomycete isolate} CDF2L1D13

DNA was isolated using a genomic DNA mini kit (Maker, City, Country) as described by Katsura et al. (2001). PCR amplification of 16S rRNA genes was done using DNA Engine Dyad $^{\circledR}$ Thermal cycler (Bio-Rad laboratories). Purified PCR products were sequenced using an $A B$ PRISM $^{\circledR}$ BigDye $^{\text {TM }}$ Terminator Ready Reaction Cycle Sequencing Kit (version 3.1, Applied Biosystems, Foster City, California, USA). The primers used for sequencing full length 16S rDNA were 518F (5'-CCA GCA GCC GCG GTA ATA CG-3') and 1492R (5' -TAC GGY TAC CTT GTT ACG ACT T-3'). For constructing the phylogenetic tree, the phylogenetic neighbors were searched using
BLASTN (Altschul et al., 1997) program against the database containing valid type strains with published prokaryotic names (Kim et al., 2012). The top thirty sequences with the highest scores were then selected for the calculation of pairwise sequence similarity using global alignment algorithm (Meyers and Miller, 1988), which was implemented at the EzTaxon-e server (http://eztaxone.ezbiocloud.net) (Kim et al., 2012).

\section{RESULTS}

\section{Isolation of cellulose degrading actinomycetes}

A total of 190 actinomycetes were isolated from the soil sample using spread plate technique on starch casein agar. Cellulase producers were screened on the starch casein agar supplemented with CMC, and the actinomycete isolate CDF2L1D13 was selected as having the highest cellulose degradation activity (Table 1) with the $\mathrm{HC}$ value of 3.93 .

Table 1: Cellulose degrading activity of the first three isolates of actinomycete which presented maximum clear zone on starch casein agar supplemented with Carboxymethyl cellulose powder.

\begin{tabular}{|c|c|c|}
\hline Isolate & $\begin{array}{l}\text { Clear zone on starch casein agar } \\
\text { supplemented with CMC }\end{array}$ & $\mathrm{HC}$ value \\
\hline CDF2L1D13 & & 3.93 \\
\hline CDF1L3C4 & & 3.04 \\
\hline CDF1L1A6 & & 2.16 \\
\hline
\end{tabular}




\section{Rice bran and CMC as carbon sources for producing $\beta$-glucosidase production}

An effect of carbon source enrichment on the $\beta$ glucosidase production by the isolate CDF2L1D13 was examined. For this purpose, enzyme activity was released in the production medium supplemented with rice bran or with carboxymethylcellulose (CMC) were compared. The isolate CDF2L1D13 produced the highest $\beta$-glucosidase activity on day 10 of culture in the rice bran-supplemented medium (Figure 1).

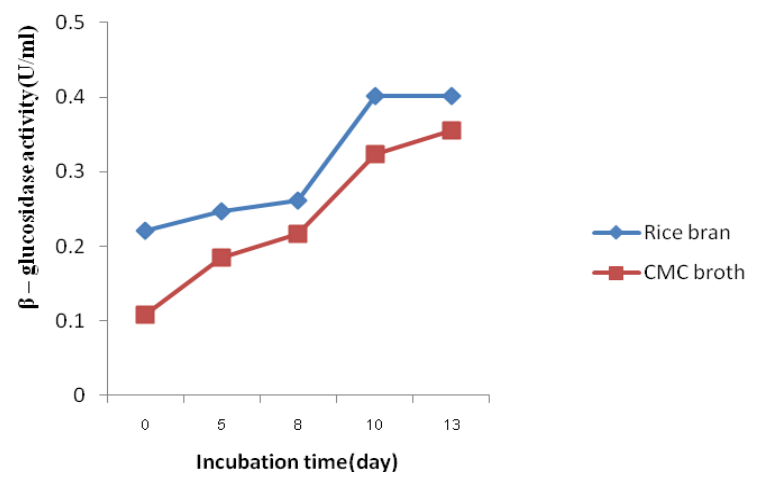

Figure 1: Enzyme activity produced by the actinomycete isolate CDF2L1D13 in the production medium supplemented with rice bran or CMC.

\section{Effect of $\mathrm{pH}$ on the $\beta$-glucosidase production}

The study of enzyme production in alternative production medium by varying of the value $\mathrm{pH}(\mathrm{pH} 4, \mathrm{pH} 7$ and $\mathrm{pH} 9)$ in the medium was done. The optimum $\mathrm{pH}$ of the medium for producing $\beta$-glucosidase was $\mathrm{pH} 7$ with the enzyme activity of $0.234 \mathrm{U} / \mathrm{mL}$ (Figure 2). On the other hand, Vaithanomsat et al. (2011) found that the optimized medium for producing maximum $\beta$-glucosidase specific activity consisted of $0.275 \%$ yeast extract, $1.125 \%$ cellobiose, and $2.6 \%$ ammonium sulfate at a $\mathrm{pH}$ value of 3.

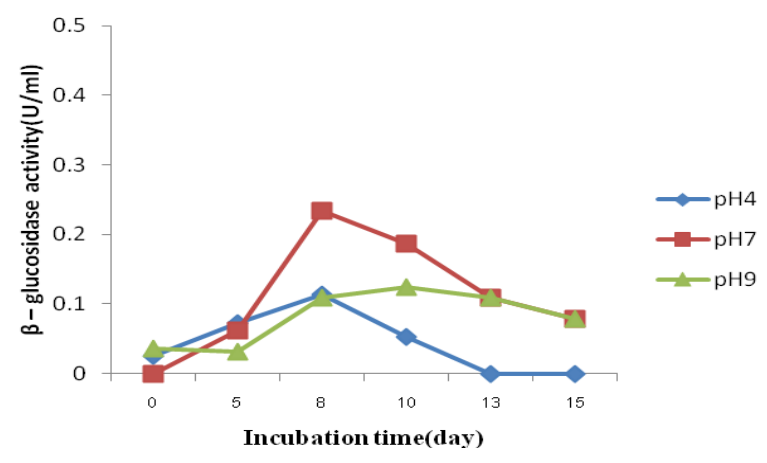

Figure 2: The optimum $\mathrm{pH}$ for the production of $\beta$ glucosidase from the actinomycete isolate CDF2L1D13.

\section{Antagonistic activities of the Actinomycete isolate CDF2L1D13 against the rice blast pathogen}

The actinomycete isolate CDF2L1D13 was able to inhibit the growth of rice blast pathogen (Pyricularia oryzae), but its inhibitory activity was not so high with the percent of inhibition of radial growth (PIRG) of $23.6 \%$ (Figure 3 ). In this report we found that the actinomycete isolate CDF2L1D13, which was identified as Streptomyces osmaniensis, could inhibit the growth of rice blast pathogen $P$. oryzae. However, its antagonistic activity was not so potent that further study is needed to see whether it could be used for controlling plant pathogens in the rice paddy.
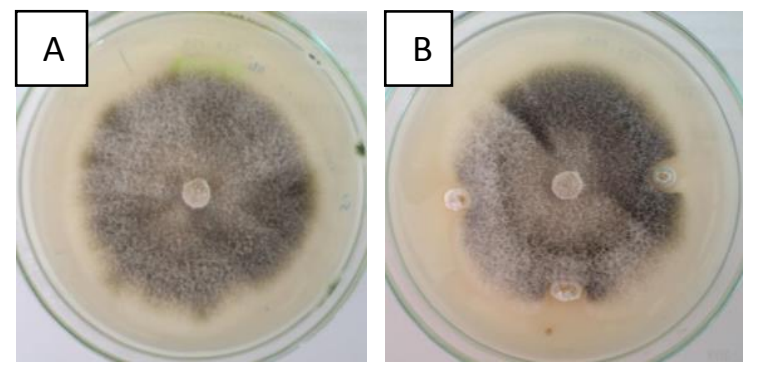

Figure 3: Antagonistic activity of the actinomycete isolate $\mathrm{CDF}_{2} \mathrm{~L}_{1} \mathrm{D}_{13}$ against rice blast pathogen, Pyricularia oryzae. $A$, control plate (rice blast pathogen alone). B, test plate: coculture of the actinomycetes isolate CDF2L1D13 with the rice blast pathogen.

Morphology and molecular identification of the Actinomycete isolate CDF2L1D13

The actinomycete isolate CDF2L1D13 was Gram positive and produced white color substrate mycelium, white color of aerial mycelium, gray spore and undulate margin color on the starch casein agar plate. Morphology under a microscope showed spiral spore chain. Identification using $16 \mathrm{~S}$ rDNA sequence revealed that the isolate CDF2L1D13 was classified as Streptomyces with $98.9 \%$ similarity with Streptomyces osmaniensis (Figures 4 and 5).
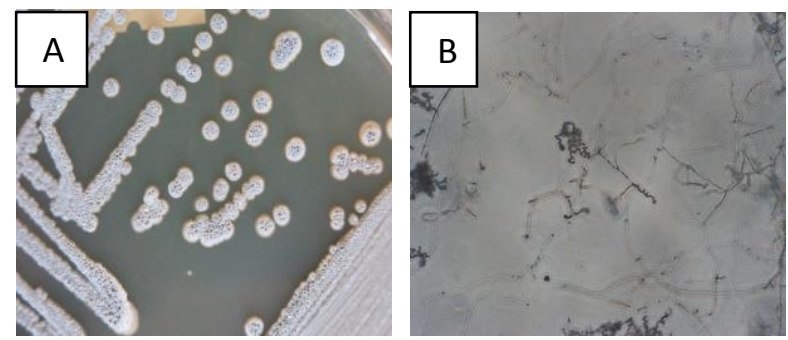

Figure 4: A, Morphology of the actinomycete isolate CDF2L1D13 on starch casein agar; B, microscopic appearance of its spore chain. 


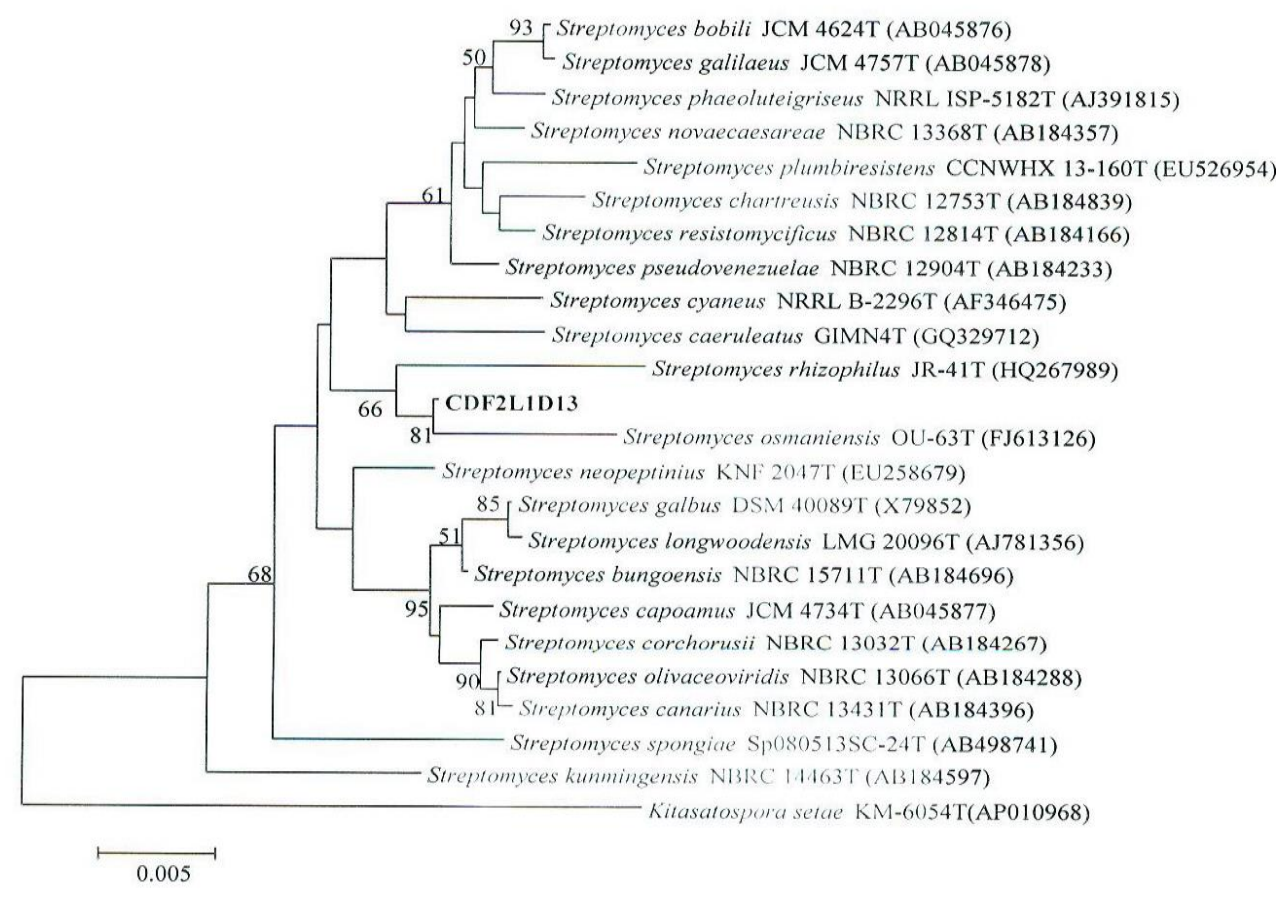

Figure 5: Phylogenetic analysis of Actinomycete isolate CDF2L1D13 using full length 16S rDNA sequence.

\section{DISCUSSION}

In this study, isolate CDF2L1D13 which was identified as $S$. osmaniensis was able to produce $\beta$-glucosidase using rice bran as a substrate. Kluepfel and Moldoveanut (1983) reported that Streptomyces sp. strain CB-12 produces a cellobiase and is able to utilize cellobiose. While $S$. flavogriseus produces not only the endo- and exoglucanases of the cellulase complex but also produces $\beta$-glucosidase. The end-product (glucose) from cellulose degradation by $\beta$-glucosidase has been used as the starter compound for producing bio-ethanol.

Using low-cost fermentation substrates for the production of the enzyme is important to reduce the cost for practical mass production. Rice bran has been used as the substrate for the mass production of various biological compounds such as $\alpha$-amylase and antibiotics. In alternative production medium, $0.5 \%(\mathrm{w} / \mathrm{v})$ rice bran as a carbon source was found to be the most efficient substrate for $\beta$-glucosidase production compared to $0.5 \%$ $(w / v)$ carboxymethylcellulose. Khanongnuch et al. (2004) found the highest laccase productivity with rice bran in liquid medium was $22 \mathrm{U} / \mathrm{g}$ substrate at 15 days cultivation.

Actinomycete are able to synthesize wide varieties of biologically active compounds such as antibiotics, pesticides, anti-parasitic compounds, enzymes like cellulase, xylanase, proteinase, chitinase and constitute a potential group of biocontrol agents. Actinomycetes are one of the important and predominant groups of soil microorganisms. There was a report showed that Streptomyces $\mathrm{sp}$. has been investigated as the antagonistic bacteria. Streptomyces sp. showed inhibitory activity against the fungal pathogen Rhizoctonia solani (Kang and Sowndhararajan, 2012).

Streptomyces osmaniensis was selected due to its high hydrolyzing activity for cellulose on CMC agar. Streptomyces osmaniensis was first reported by Reddy et al. (2010) and it was isolated from garden soil collected on the campus of Osmania University in Hyderabad, southern India.

Its optimum $\mathrm{pH}$ and temperature for producing $\beta$ glucosidase were $\mathrm{pH} 7$ and $30^{\circ} \mathrm{C}$. Addition of rice bran, which is an agricultural waste, as a carbon source and peptone as an organic nitrogen source enhanced the $\beta$ glucosidase production by $S$. osmaniensis. Moreover, $S$. osmaniensis has shown antagonistic activity against rice blast fungal pathogen.

\section{ACKNOWLEDGEMENTS}

This work was supported by the Khon Kaen University grant under the Plant Genetic Conservation Project of the Royal Initiation of Her Royal Highness Princess Maha Chakri Sirindhorn (RSPG), the Bureau of the Royal Household. We would like to thank for some part of financial support from the Applied Microbiology Resource Research Group, Faculty of Science, Khon Kaen University, Thailand. The authors wish to thank Prof. Dr. Yukifumi Nawa for preliminary correcting on manuscript. 


\section{REFERENCES}

Altschul, S. F., Madden T. L., Schaeffer A. A., Zhang J., Miller, W. and Lipman, D. J. (1997). Gapped BLAST and PSI-BLAST: A new generation of protein database search program. Nucleic acids Research 25, 3389-3402.

Dick, R. P., Breakwelland D. P. and Turco R. F. (1996). Soil enzyme activities and biodiversity measurements as integrative microbiological indicators. In: Methods for Assessing Soil Quality Special Publication No. 49, Doran, J. W. and Jones, A. J. (eds.). Soil Science Society America, Madison, WI, USA. pp. 247-271.

Jeffrey, L. S. H. (2008). Isolation, characterization and identification of actinomycetes from agriculture soils at Semongok, Sarawak. African Journal of Biotechnology 7(20), 3697-3702.

Kang, S. C. and Sowndhararajan, K. (2012). In vitro antagonistic potential of Streptomyces sp. AM-S1 against plant and human pathogens. Journal of Agricultural Chemistry and Environment 1(1), 41-47.

Katsura, K., Kawasaki, H., Potacharoen, W., Saono, S., Seki, T., Yamada, Y., Uchimura, T. and Kamagata, K. (2001). Asaia slamensis sp. nov., an acetic acid bacterium in the $\alpha$-Proteobacteria. International Journal Systematic Evolutionary Microbiology 51, 559563.

Khanongnuch, C., Chawachart, N., Watanabe, T. and Lumyong, S. (2004). Rice bran as an efficient substrate for Laccase production from thermotolerant basidiomycete Coriolus versicolor strain RC3. Fungal Diversity 15, 23-32.

Kim, O. S., Cho, Y. J., Lee, K., Yoon, S. H., Kim, M., Na, H., Park, S. C., Jeon, Y. S., Lee, J. H., Yi, H., Won, S. and Chu, J. (2012). Introducing EzTaxon-e: A prokaryotic 16S rRNA gene sequence database with phylotypes that represent uncultured species. International Journal Systematic Evolutionary Microbiology 62, 716-721.

Kluepfel, D. and Moldoveanut, N. (1983). Comparison of $\beta$-glucosidase activities in different Streptomyces strains. Applied and Environmental Microbiology 46(1), 17-21.

Meyers, E. W. and Miller, W. (1988). Optimal alignments in linear space. Computer Applications in the Biosciences 4, 11-17.

Reddy, T. V., Mahmood, S., Idris, M. M. and Ciesielski, S. (2010). Streptomyces osmaniensis sp. nov. isolated from soil. International Journal Systematic Evolutionary Microbiology 60, 1755-1759.

Sekar, T. and Mohanraj, G. (2013). Isolation and screening of actinomycetes from marine sediment for their potential to produce antimicrobials. International Journal Life Sciences. Biotechnology and Pharma Research 2(3), 115-126.

Tabatabai, M. A. (1994). Soil enzymes. In: Methods of Soil Analysis. Part 2: Microbial and Biochemical Properties. Weaver, R. W, Angel, J. S. and Bottomley P. S.(eds.). Soil Science Society America, Madison, WI, USA. pp. 775-833.
Tako, M., Lung, S., Krisch, J., Papp, T. and Vagvolgyi, C. (2009). Production of cellulolytic enzymes on agricultural waste by different zygomycetes. Journal of Engineering Annals of Faculty of Engineering Hunedoara 4, 169-172.

Vaithanomsat, P., Songpim, M., Malapant, T., Kosugi, A., Thanapase, W. and Mori, Y. (2011). Production of $\beta$-glucosidase from a newly isolated Aspergillus species using response surface methodology. International Journal of Microbiology 1, 1-9.

Veiga, M., Esparis, A. and Fabregas, J. (1983). Isolation of cellulolytic actinomycetes from marine sediments. Applied and Environmental Microbiology. 46(1), 286-287.

Živkovic, I. S., Stojanovic, S., Ivanovic, Ž., Gavrilovic, V., Popovic, T. and Balaz, J. (2010). Screening of antagonistic activity of microorganiams against Collectotrichum acutatum and Collectotrichum gloeosporioides. Archives of Biological Science Belgrade 62(3), 611-623. 